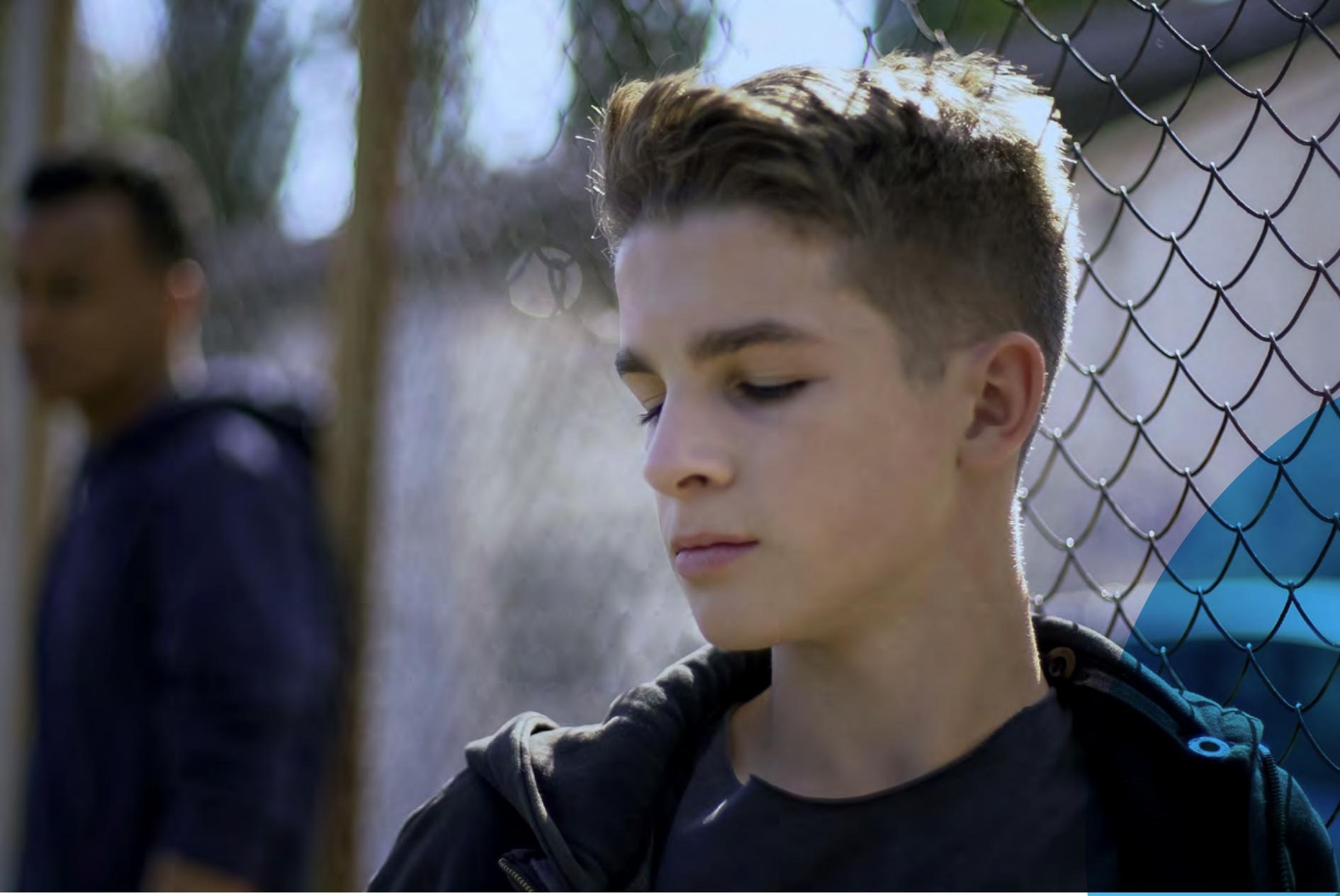

\title{
Is formal processing through the juvenile justice system linked with an increased risk of reoffending?
}

By Dr. Jessica Edwards

Data from a new study published in the Journal of Child Psychology and Psychiatry support that formally processing adolescents through the juvenile justice system after their first arrest for a mild-to-moderate crime is linked with an increased risk of reoffending. Strikingly, callous-unemotional (CU) traits might moderate this effect.

To generate these data, Emily Robertson and colleagues recruited $>1,200$ first-time male offenders (mean age 15.12 years) from three regions across the USA who had committed a mild-to-moderate crime. They then recorded whether these offenders exhibited antisocial behaviours at 6 weeks after their arrest, and then at 6 -month intervals for 3 years. To do so, they collected self-report data on offending and official records of juvenile and adult arrests. 
"For first-time juvenile offenders who have not committed a serious violent crime, our results suggest that diverting them from or minimizing their contact with the juvenile justice system can greatly improve their outcomes, including by making them less likely to commit future crimes and to be re-arrested", says Robertson. "What's more, our study provides a number of improvements over past research. For example, we followed youth after their first arrest for an extended period of time, and we controlled for numerous potential confounds, such as the severity of the offence for which they were arrested and a number of pre-existing vulnerabilities (such as their intelligence, the quality of parenting they experienced, the quality of their neighbourhood)."

Next, Robertson et al. tested whether CU traits moderated this relationship between the processing decision and future antisocial behaviours. Here, they found that those with elevated CU traits at baseline showed higher rates of antisocial behaviour over the study period, regardless of how the juvenile justice system processed their case. Importantly, formal processing through the juvenile justice system was more strongly linked with later antisocial behaviour in those with lower baseline levels of CU traits.

"Previous studies that looked at the harmful effects of juvenile justice system involvement did not consider whether or not the adolescent was elevated on CU traits," explains Robertson. "As a result, the harmful effects of processing kids through the system and the beneficial effects of diverting them away from the system might have been underestimated for the vast majority of youths who do not show elevations on these traits".

The researchers hypothesize that interventions to reduce severe behaviour problems that are effective for adolescents with normative $\mathrm{CU}$ traits might not work as well for those with high levels of $\mathrm{CU}$ traits. As such, explorations into potential novel interventions for youth with elevated CU traits in the justice system should continue.

\section{Referring to:}

Robertson, E.L., Frick, P.J., Ray, J.V., Thornton, L.C., Myers, T.D.W., Steinberg, L. \& Cauffman, E. (2020), Do callousunemotional traits moderate the effects of the juvenile justice system on later offending behavior? J. Child Psychol. Psychiatr. doi: 10.1111/jcpp.13266.

\section{Glossary:}

\section{Callous-unemotional (CU) traits: :}

includes limited guilt and empathy, constricted displays of emotion, and reduced concern over performance in important activities.

\begin{abstract}
"For first-time juvenile offenders who have not committed a serious violent crime, our results suggest that diverting them from or minimizing their contact with the juvenile justice system can greatly improve their outcomes, including by making them less likely to commit future crimes and to be re-arrested"
\end{abstract}

